\title{
El documentalista de programas de televisión: horizontes profesionales
}

\author{
Por Silvia Ripoll-Mont y Luisa Tolosa-Robledo
}

\begin{abstract}
Resumen: Se analizan las tendencias profesionales de los documentalistas de programas de televisión y las oportunidades que surgen en el mercado laboral gracias al arraigo del consumo multimedia y de la multiplicación y diversificación de medios de divulgación (mass media, internet, empresas culturales, televisión digital terrestre...). Se constata la promoción, proyección y creación de empresas virtuales de investigadores audiovisuales (recherchistes, researchers) en el panorama internacional mediante el estudio de cuatro casos. Son expertos investigadores, la mayoría freelance, con mucha experiencia en la localización de imágenes, negociación de licencias y liquidación de los derechos a terceros en la tarea de documentar producciones multimedia. La ampliación de horizontes de difusión, la conquista de clientes heterogéneos y los archivos digitales pronostican nuevos caminos de evolución y un futuro esperanzador para esta especialidad en la era digital.
\end{abstract}

Palabras clave: Documentalistas de programas, Televisión, Documentalistas audiovisuales, Perfil profesional, Mercado multimedia, Internet, Profesionales autónomos.

Title: The television programme researcher: the professional outlook

Abstract: Professional trends for television programme researchers and opportunities that arise in the labour market due to the widespread media consumption and the increasing number of diverse media (mass media, internet, cultural industries, Digital Terrestrial Television...) are analysed. We present the promotion, projection and creation of virtual en-

terprises of audiovisual researchers in the international arena using four case studies. These research experts, most of them freelancers, have extensive experience in locating images, negotiating licenses and liquidating rights to third parties as part of the task of documenting multimedia productions. The expanding broadcast horizons, the conquest of heterogeneous customers and the use of digital archives predict new development paths and a bright future for this profession in the digital age.

Keywords: Freelance researchers, Television, Audiovisual archivists, Professional profiles, Multimedia market, Internet.

Ripoll-Mont, Silvia; Tolosa-Robledo, Luisa. "El documentalista de programas de televisión: horizontes profesionales". El profesional de la información, 2009, mayo-junio, v. 18, n. 3, pp. 341-347.

DOI: 10.3145/epi.2009.may.13

\section{Introducción}

DOCUMENTALISTA DE PROGRAMAS DE TELEVISIÓN es una profesión joven que nace en la década de los setenta del siglo XX y se consolida en España a partir de los ochenta con la creación de las televisiones autonómicas y privadas. Se trata de la especialización en la búsqueda de imágenes en movimiento, material gráfico e información escrita para una producción audiovisual.

Responde a las necesidades de la producción en televisión y el uso constante de material documental para ilustrar proyectos audiovi- suales. A su vez, favorece la recuperación de la memoria colectiva mediante la investigación y explotación del yacimiento de imágenes, entre otros bienes del patrimonio histórico y cultural, que enriquecen la reconstrucción de los hechos más relevantes en la tarea de documentar producciones audiovisuales. 
En el panorama internacional tales profesionales se denominan:

- Recherchistes en Francia y Canadá. El origen del término es canadiense, donde la profesión está muy reconocida. fona.

- Researchers en el área angló-

- Documentalistas de programas de televisión en España.

A diferencia del documentalista audiovisual (documentaliste audiovisuel, audiovisual archivist...) que trabaja en centros de documentación audiovisual elaborando el archivo histórico documental, el documentalista de programas se especializa en la búsqueda del material documental necesario para la realización de una producción audiovisual.

\section{"Los documentalistas de programas están especializados en la búsqueda de imágenes en movimiento, material gráfico e información escrita para una producción audiovisual"}

Es un perfil que además no se dedica únicamente a colaborar en la producción de programas de televisión, sino que puede participar en cualquier proyecto que requiera investigaciones documentales, tales como producciones cinematográficas, campañas de publicidad, vídeos para empresas o instituciones, exposiciones culturales etc.

En el mundo anglosajón la palabra researcher se acompaña por el tipo de documentos en que están más especializados: film, video, visual, stills, picture, iconography, manuscript... researcher.

Según Francisco Quintanar "el trabajo que realiza la persona

\section{Documentalista de programas y documentalista audiovisual}

El "documentalista de programas" trabaja para una producción determinada, por ejemplo, en series de televisión que requieren un uso intensivo de documentación, como Cuéntame. Suelen ser freelance o trabajan para productoras de TV, no para cadenas de TV. Es decir, los contrata habitualmente la productora del programa para hacer las labores de documentación de ese programa. Su situación laboral no se parece a la de los documentalistas de plantilla de una televisión, y su cometido profesional es más específico, hacen por tanto mucha labor de investigación. Véase el ejemplo de un documentalista de la serie

Periodistas en: "Documenta, que algo queda". El guionista hastiado, 16 abril 2009.

http://elguionistahastiado.espacioblog.com/post/2009/04/16/documenta-algo-queda

"Documentalista audiovisual" es una figura más genérica que designa habitualmente al documentalista que trabaja para una cadena de televisión u otro medio. Es decir, trabajan para la empresa, no para un programa concreto, y sus funciones pueden ser muy diversas. que llamamos 'documentalista de programas' en televisión, era realizado originariamente por el equipo de producción, que buscaba aquellas ‘cosas de archivo' (libros, grabados, dibujos, fotografías, imágenes antiguas en cine o vídeo...) que hacían falta para producir una obra [...]. La especialización y la diversificación en las tareas profesionales creó este nuevo tipo de documentalista".

\section{http://www.pacoquintanar.com/} intro.htm

En España el documentalista de programas es conocido y habitual en el entorno televisivo, al cual está restringido. Es conocido genéricamente como documentalista $\mathrm{y}$ así aparece en los títulos de crédito de la producción audiovisual, independientemente de que se emita en televisión o se distribuya por otros canales.

\section{Entorno laboral}

Las relaciones contractuales se pueden sintetizar en el esquema de la tabla 1.

Los documentalistas de programas trabajan para un programa de televisión en concreto, independientemente de si son contratados por la empresa emisora, por productoras, o en calidad de autóno-

"Los nuevos modos y medios de acceso y difusión de la información benefician y abren caminos

a los documentalistas audiovisuales"

\section{Empresa de contratación}

- Televisión pública o privada

Departamento de producción propia de programas (o análogo)

Centro de documentación de televisión

- Productoras externas (generalmente privadas)

- Otras empresas e instituciones

- Freelance o autónomo

\section{Tipos de contratos}

- Según la duración de la jornada laboral:

A tiempo completo

A tiempo parcial

- Según la duración del contrato:

Contrato indefinido

Contrato temporal

Contrato por obra o servicio

Tabla 1. Relaciones contractuales 


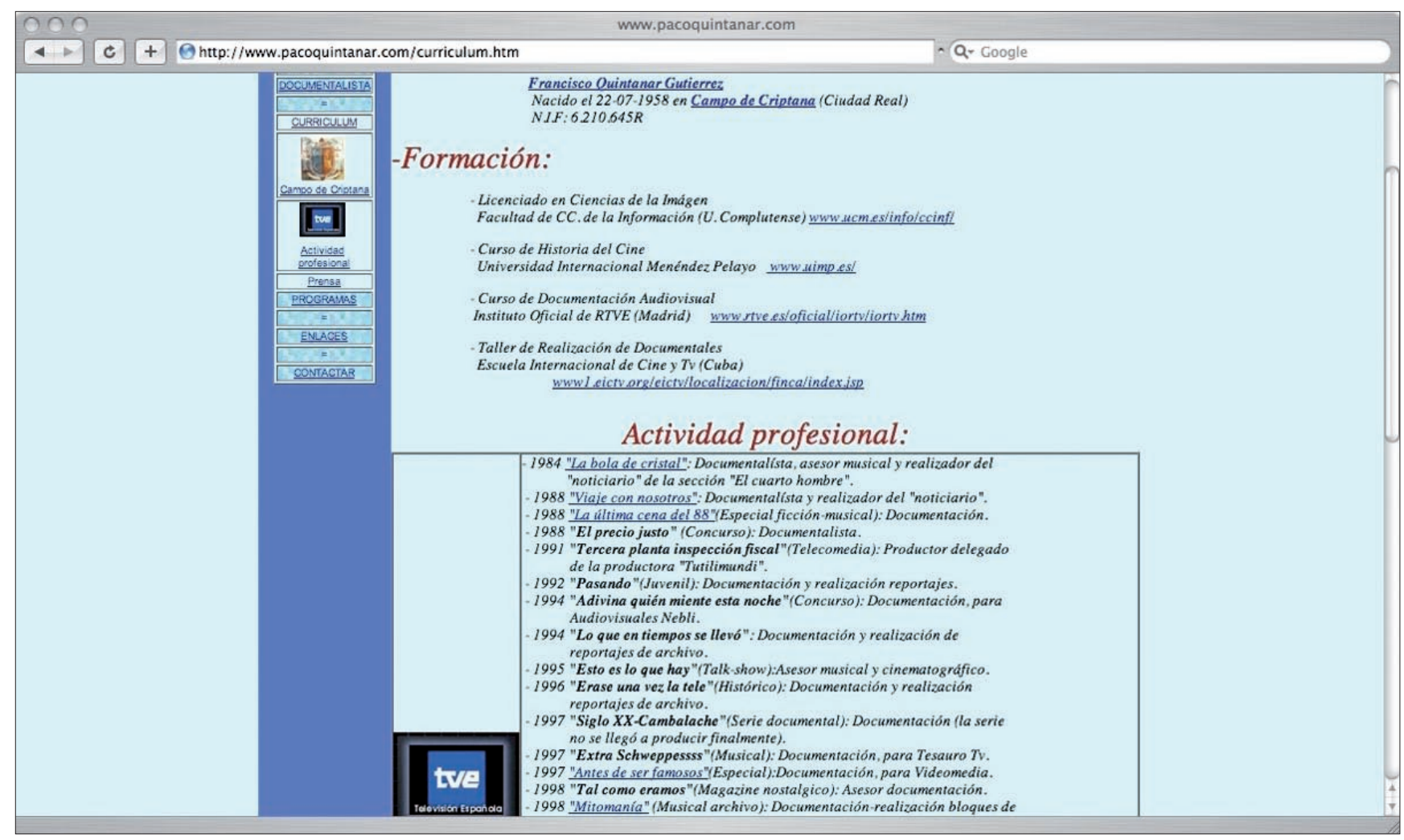

Figura 1. Curriculum vitae de documentalista de programas de televisión $\mathrm{http}: / /$ www.pacoquintanar.com/intro.htm

mos. En algunos casos colaboran simultáneamente en varios proyectos audiovisuales a tiempo parcial e incluso pueden estar trabajando en un programa desde el departamento de documentación de la televisión, si su relación contractual le permite la compatibilidad de tareas.

La modalidad de contratación más habitual es por obra o servicio determinado, cuya duración se desconoce por depender de su éxito de audiencia, a la política de programación de la empresa, etc. Hay programas que duran una emisión y otros que continúan en la parrilla de programación durante varias temporadas seguidas.

Muchos de los contenidos de TV están creados por productoras debido a las políticas de subcontratación que se han ido implantando desde los 90s en España. Los programas emitidos son el resultado de producciones externas -delegada o propia y en coproducción- financiadas total o parcialmente por las cadenas emisoras, y producciones ajenas cuyos programas han sido comprados a productoras y distribuidoras. En todos estos casos, la cadena de televisión detenta los derechos de emisión y/o explotación.

\section{Documentalistas freelance: estudio de casos}

El ejercicio como freelance (trabajo como autónomo, por cuenta propia) es muy conocido y ejercido en el entorno de los medios de comunicación (fotógrafos, periodistas...), pero con internet y la posibilidad del teletrabajo todavía se ha expandido más.

Con el objeto de estudiar las tendencias profesionales se han recabado datos de los curriculum vitae de documentalistas, agencias de recherchistes, y webs de asociaciones y federaciones audiovisuales internacionales.

Caso 1: Documentalista de programas de televisión de origen español

El primer perfil estudiado es el de Francisco Quintanar, licenciado en ciencias de la imagen por la Universidad Complutense de Madrid, que ha hecho cursos de formación en historia del cine, un taller de realización de documentales y un curso de documentación audiovisual en el Instituto Oficial de RTVE.

Ha realizado más de cuarenta colaboraciones en producciones de entretenimiento y divulgación destinadas al consumo televisivo. Ha participado en proyectos emitidos por las principales cadenas de televisión de España (TVE, Canal sur, Telemadrid, Antena3, Tele5, EITB, Vía digital) desde el año 1984 hasta la actualidad. Como freelance ha trabajado en las productoras Tutilimundi, Audiovisuales Nebli, Tesauro TV, Videomedia, Magnolia Prod., Summers Prod., Orquesta Mondragón SL, Goleen Prod., etc. Ha compaginado dichas tareas con otras funciones y cargos de responsabilidad (asesor musical, realizador de vídeos, productor delegado, guionista, subdirector y director del programa).

http://www.pacoquintanar.com/ intro.htm 
Caso 2: Visual Researchers Society of Canada (VRSC) o Association des Recherchistes en audiovisuel du Canada (ARAC)

Se trata de una asociación de 80 documentalistas que promueve la excelencia en el campo de la investigación visual en todos los medios de comunicación.

Fija normas de calidad, potencia el talento, las habilidades y la visión para los negocios, el intercambio de ideas, y emite directrices sobre las condiciones de trabajo de los asociados.

\section{"Proliferan los documentalistas freelance con espíritu emprendedor que crean empresas en internet"}

Desde septiembre de 2007 dispone de una web para que los productores, editores y otros profesionales que busquen contratar a un investigador visual, puedan seleccionarlo según sus necesidades de entre los miembros de la asociación.

El directorio proporciona el contacto con los investigadores, la sede desde donde trabajan y los tipos de documentos, materias y formatos televisivos en los que están especializados.

\section{http://www.visualresearch.ca/en/}

Caso 3: Federation of Commercial Audiovisual Libraries International (Focal)

Creada en el Reino Unido en 1985 por la BBC y el Institut National de l'Audiovisuel (INA) con el fin de promocionar la comercialización de documentos de archivos audiovisuales en los mercados internacionales. Focal cuenta con más de 300 miembros del sector público y privado de los cinco continentes: documentalistas autónomos, archivos audiovisuales y fílmicos, cadenas de televisión, productores, empresas relacionadas con la industria audiovisual y el cine, abogados especiali- zados en medios de comunicación y cuestiones de derechos de autor.

Focal representa a todos sus miembros para su mutuo beneficio comercial. Los principales servicios son la consulta, la venta de imágenes, el asesoramiento y los contactos con profesionales audiovisuales. Entre otras actividades, publica la revista Archive zones, celebra seminarios, talleres y premios internacionales que tienen por objeto promover el uso de imágenes de archivo en los medios de comunicación.

\section{"Focal ofrece consultoría y asesoramiento, venta de imágenes, y contactos con profesionales audiovisuales"}

Facilita a los usuarios el directorio de todos sus asociados, destacando en este punto el dedicado a los 130 freelance researchers,

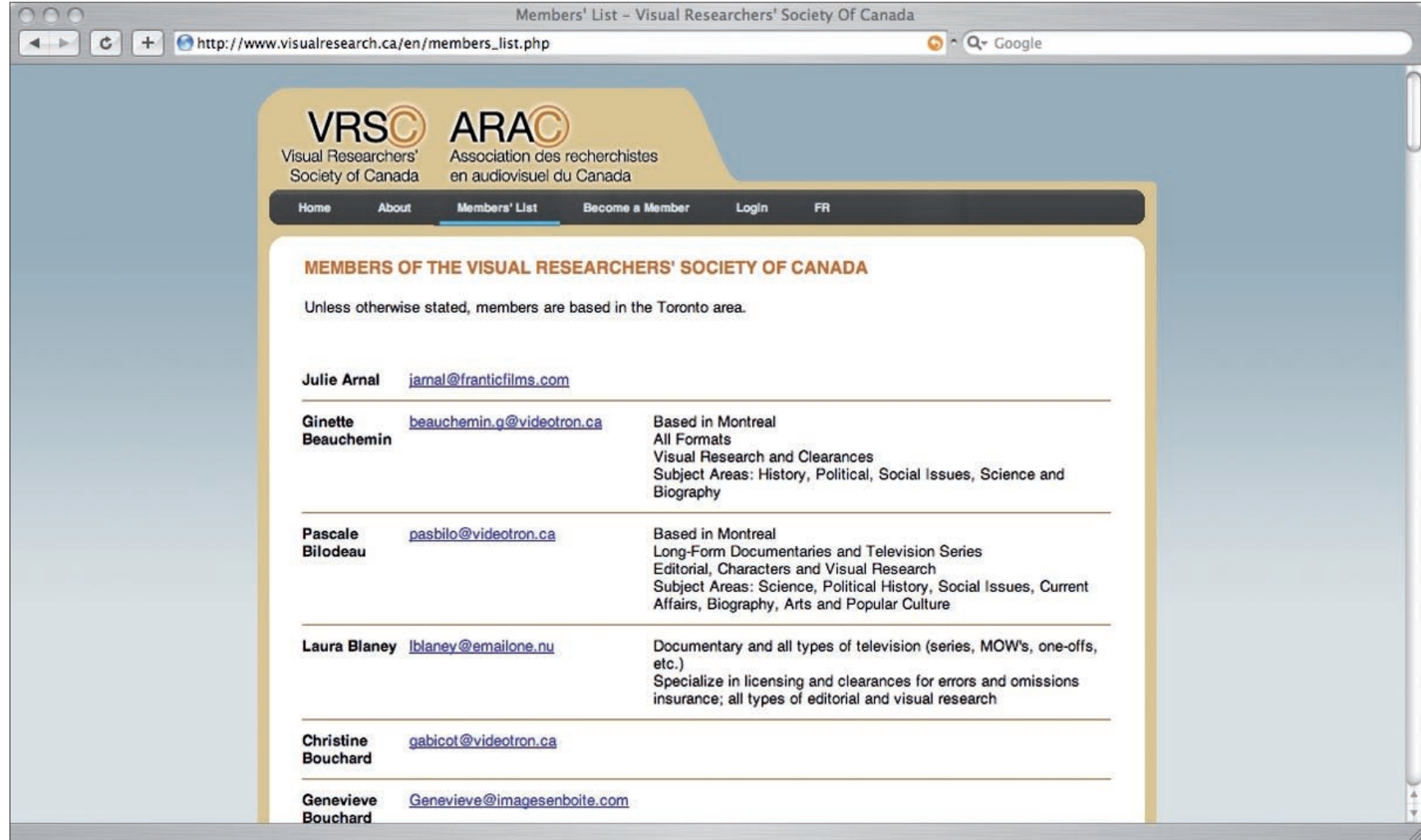

Figura 2. Visual Researchers Society of Canada VRSC/ARAC http://www.visualresearch.ca/en/ 


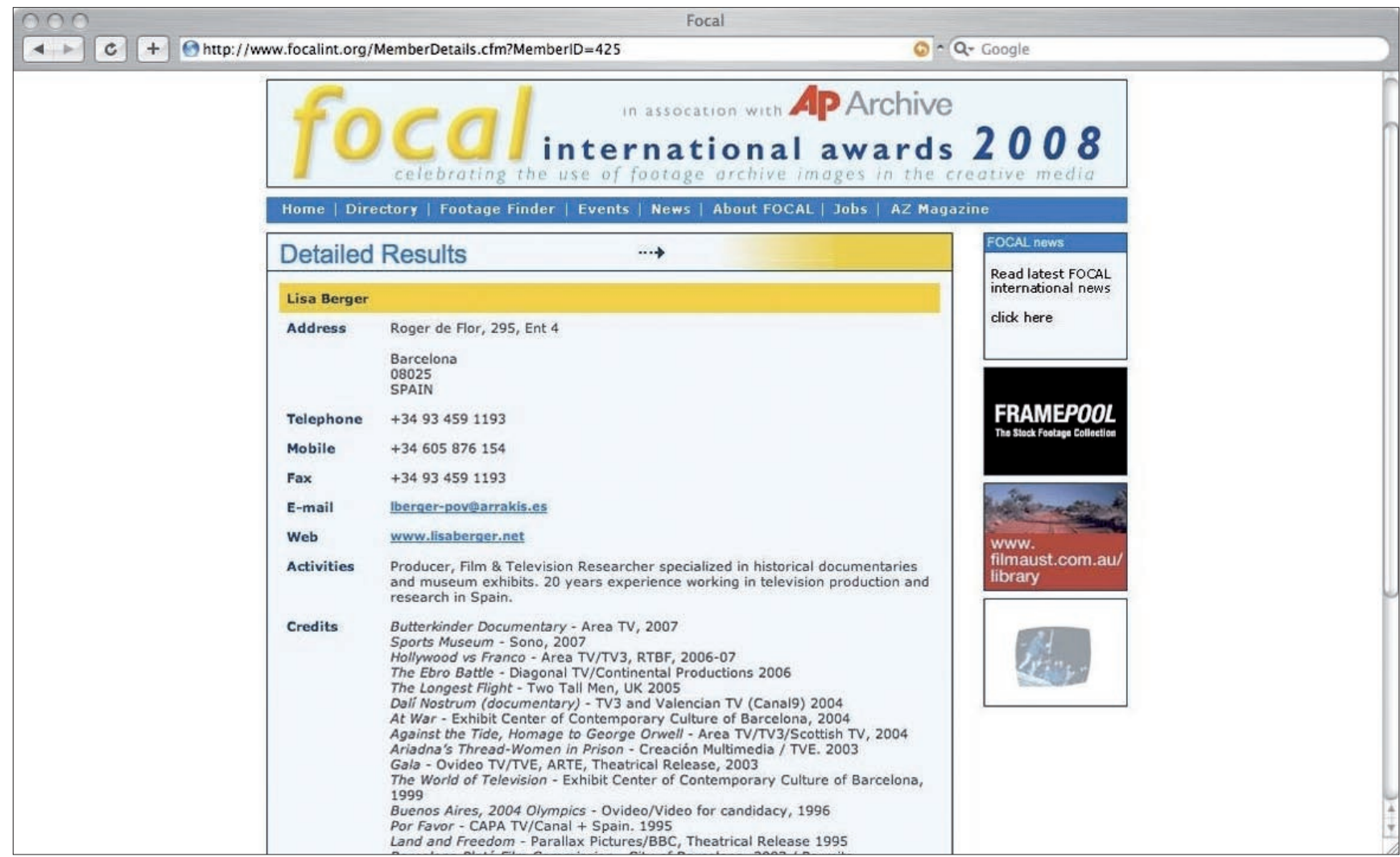

Figura 3. Freelance researcher de la asociación Focal http://www.focalint.org/

en el cual se aportan datos personales y la trayectoria profesional y se aprecia la extensa experiencia de los asociados mediante la enumeración de los proyectos audiovisuales emitidos en las más importantes televisiones del mundo. En la figura 3 se muestra la única asociada researcher, Lisa Berger, con domicilio en España.

\section{http://www.focalint.org/}

\section{Caso 4: XYZèbre}

Se trata de una agencia francesa de recherchistes, documentalistas audiovisuales y de iconographes con más de veinte años de experiencia. Cuenta en su haber con centenares de proyectos testimonio de su fecunda y fructuosa productividad en este campo de investigación. Además realiza cursos de formación y asesoramiento en documentación audiovisual (gestión, herramientas documentales, cuestiones jurídicas, estudios de mercado...).

Es una agencia de reconocido prestigio si nos fijamos en el listado de clientes (figura 4) y en los proyectos realizados. Documentan y participan en proyectos que engloban todos los medios de comunicación de masas y culturales (televisión, museos, exposiciones, publicidad, películas, prensa, edición impresa, edición multimedia, teatro, vídeos institucionales y corporativos, eventos, festivales, conmemoraciones culturales, sitios web...). Su investigación abarca todas las disciplinas (economía, geopolítica, sociedad, historia, arte, ciencias, literatura...) y todos los períodos de la historia.

http://www.xyzebre.com/

\section{Evolución profesional y diversificación de clientes}

Es difícil establecer comparaciones entre los casos estudiados porque son asimétricos y no presentan la misma información, pero sí que permiten entrever las tendencias de la profesión.

Predominan los documentalistas freelance con formación universitaria en ciencias sociales y hu- manidades. Se caracterizan por su inquietud, mentalidad polivalente y dinámica, entre otras cualidades que influyen positivamente en la proyección laboral de esta especialidad. Todos han trabajado en o para la televisión en un amplio abanico de géneros y formatos, y en otros medios de difusión; son expertos en la búsqueda y adquisición de materiales multimedia, y en negociar los acuerdos de cesión. Se observa un aumento en la oferta y la demanda de profesionales a escala internacional.

Las asociaciones y federaciones audiovisuales van más allá de sus actividades tradicionales, y utilizan la Red como plataforma para propiciar el encuentro entre sus profesionales y los productores según sus respectivas necesidades. Incluso potencian entre sus clientes la comercialización de documentos audiovisuales de los archivos fílmicos y televisivos de los asociados (Focal).

La mayoría de los archivos digitales comerciales en internet fa- 


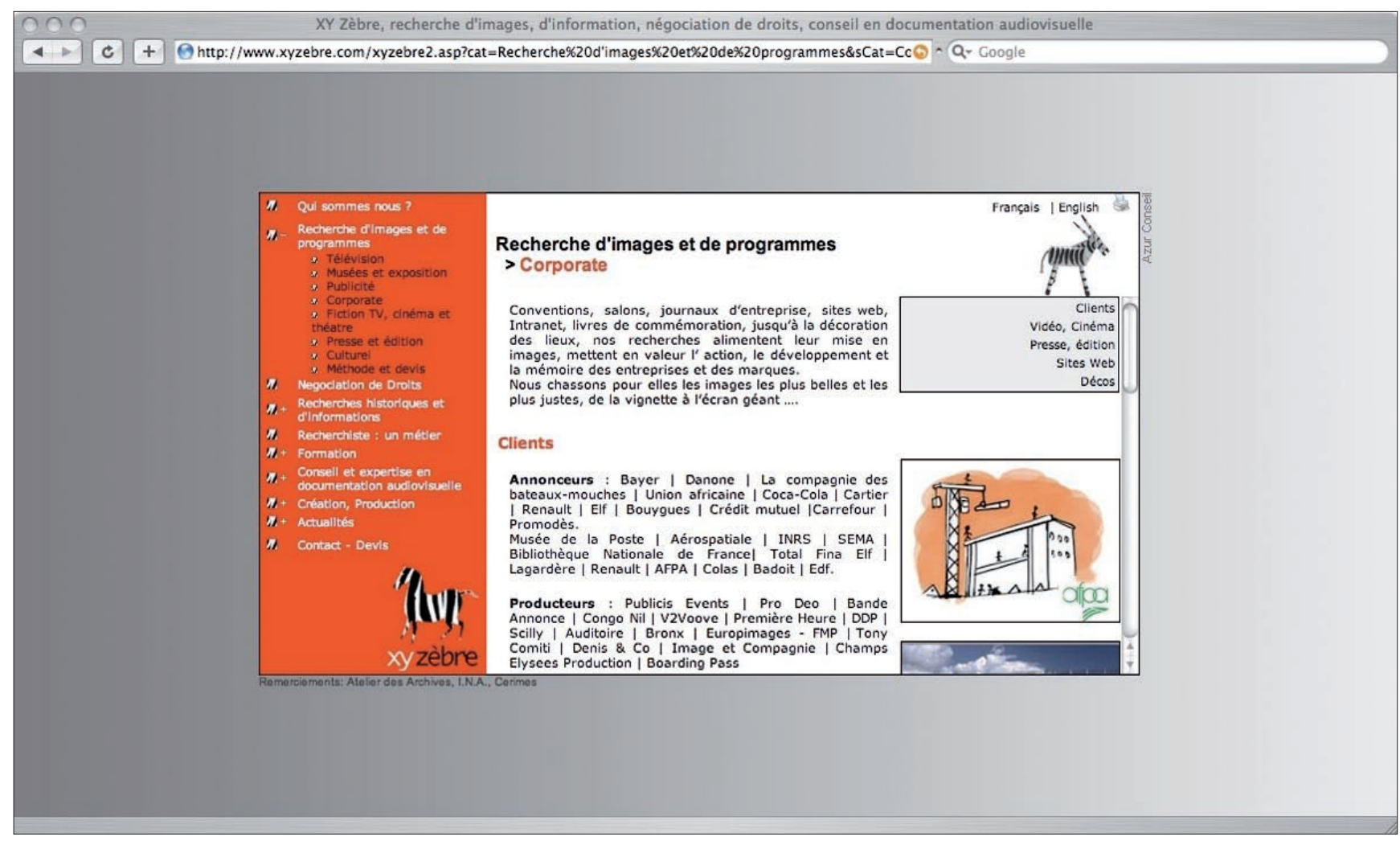

Figura 4. XYZèbre

http://www.xyzebre.com/

\section{"Es una especialidad laboral en expansión y crecimiento debido al afianzamiento de la Web y la aparición de la TDT"}

cilitan, previo pago, el servicio de expertos en la localización del material audiovisual, para clientes que no pueden dedicar su tiempo a la búsqueda documental o que desconocen los fondos documentales o estrategias de interrogación en las bases de datos, librerías digitales, etc.

Es el perfil de una profesión muy joven, a veces desconocida, pero con un panorama laboral alentador, repleto de trabajadores autónomos, que aunque viven la incertidumbre laboral propia de estos tiempos y de ser autónomos, reciben compensaciones por los proyectos en los que colaboran y por el equipo con el que trabajan.

De todas las fuentes consultadas, subrayamos la citada agencia de recherchistes XYZèbre de Francia que opera desde internet con una actividad y una trayectoria laboral prolífica de proyección internacional. Plantean el perfil de un profesional que ha traspasado las fronteras de la televisión y compatibiliza otros trabajos multidisciplinares.

Es una agencia abierta a otros mercados, que ha suscitado y multiplicado la diversidad de clientes (instituciones públicas y privadas, empresas de publicidad, directores de cine, productores...), y sus colaboraciones se difunden no sólo en los medios de comunicación de masas sino en todo tipo de empresas e instituciones.

La agencia XYZèbre o los miembros asociados a Focal, entre otros casos vistos, constituyen un paradigma de las tendencias europeas de nuestra especialidad. Su visibilidad contribuye al afianzamiento y reconocimiento de los profesionales que se dedican a la investigación multimedia, y a la apertura de nuevos mercados laborales que ignoran o desconocen nuestro oficio.
Probablemente la línea de evolución natural de esta profesión y su tendencia están representadas en el modelo de la agencia XYZèbre. No parece que vaya a extinguirse la profesión de documentalista de programas. Los ejemplos comentados auguran su expansión y adaptación a las nuevas tecnologías, nuevos hábitos y roles laborales, nuevas tendencias y realidades del mercado multimedia.

\section{"La digitalización de los archivos televisivos y fílmicos y su presencia en internet inciden favorablemente en esta figura profesional"}

\section{Conclusiones}

Los nuevos modos de acceso a la información y los nuevos medios de difusión (internet...) benefician y abren caminos a los documentalistas 
audiovisuales. En el caso de España se observa una falta de promoción profesional con respecto a los colegas europeos, y un retraso en detectar las múltiples oportunidades y los potenciales clientes para el ejercicio de una profesión en plena evolución que coincide con la hegemonía y hábitos de consumo multimedia.

Proliferan los documentalistas freelance, que con espíritu emprendedor crean empresas especializadas en internet, así como documentalistas audiovisuales que se promocionan desde las federaciones y asociaciones internacionales, en las que se protege la excelencia de los trabajos audiovisuales y el uso racional en la explotación de los documentos. Al mismo tiempo, protegen la memoria visual cumpliendo los requisitos de la Ley de la Propiedad Intelectual.

Se puede concluir que es una especialidad laboral en expansión y crecimiento debido al afianzamiento de la Web, la aparición de la TDT (televisión digital terrestre) y la consiguiente multiplicación de canales televisivos y de programas; la consolidación de producciones multimedia y la digitalización de los archivos televisivos y fílmicos, y su presencia en internet, inciden favorablemente en esta figura profesional.

Se caracterizan por su polivalencia en las tareas realizadas, tales como:

- Asesorar y gestionar contenidos multimedia en programas televisivos.

- Establecer y cuidar las relaciones con los archivos, centros de documentación, museos, hemerotecas etc., públicos y privados, con los coleccionistas, etc.

- Explotar el material audiovisual histórico (noticiarios...) o de actualidad en archivos digitales extranjeros presentes en la Red.

- Identificar y negociar los derechos recogidos en la Ley de la
Propiedad Intelectual para documentos audiovisuales, entre otros materiales.

Para ello, los documentalistas de programas poseen -entre otrasestas cualidades:

- Espíritu de investigación y capacidad para generar empatía y sinergia con el equipo de trabajo.

- Habilidades y conocimientos para transformar una idea o un texto (guión...) en material icónico.

- Proactividad, adelantándose a las necesidades documentales y ela- borando previsiones informativas.

- Saber buscar nuevas oportunidades laborales abriéndose a mercados multidisciplinares, y fidelizando a los nuevos clientes.

\section{Silvia Ripoll-Mont; Luisa Tolosa- Robledo}

Escuela Técnica Superior de Ingeniería Informática (FI)

Universitat Politècnica de València.

Camino de Vera, s/n. 46022 Valencia

marimon@har.upv.es

ltolosa@upvnet.upv.es

\title{
Le ayudamos a crear DIGIBIS Bibliotecas Virtuales
}

\author{
desde la digitalización de materiales bibliográficos \\ hasta la asignación de metadaios y su implementación \\ en la red, conforme a la normativa internacional
}

\section{Productos para crear Bibliotecas Digitales y Virtuales}

D|e|B|: 5.0

Solución avanzada para la creación de Bibliotecas Digitales y la Gestión Bibliotecaria Multilingüe

DICIARCH 1.6

Sistema digital de descripción y gestión archivística

Digifalización avanzedo Con asignación dinámica de metadatos

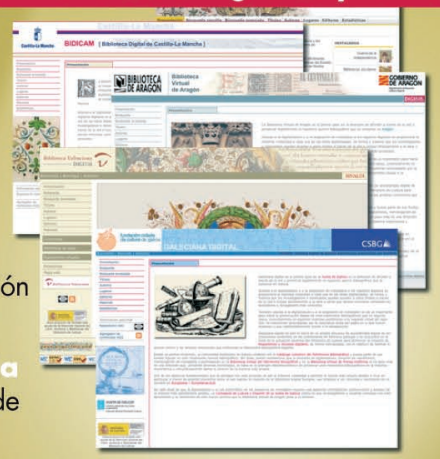

OAsls-PMH 2.0

Sistema integrado de recolección de diversos esquemas de metadatos:

DCMI sin cualificar MARC 21

EAD

mod_OAl

Implementación de las directrices DRIVER
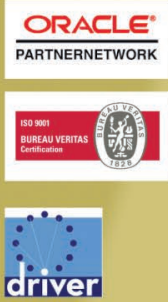

Recolección en la Web para Entidades e Instituciones de Memoria en OAI-PMH y Dublin Core e intercambio de metadatos en MEIS (diferentes Profiles)

- Consultoría y mappings a DCMI para implementación en repositorios OAl v2.0

Tecnologías abiertas para la creación, recuperación y recolección de metadatos (MARCXML, DCMI y RDF) Repositorios Institucionales para Preservación Digital a largo plazo mediante PREMIS y OAIS ISO 14721

- Reconocimiento Óptico de Caracteres OCR y generación dinámica de MEIS/Alio

- Servidor adicional de SRU Search/Retrieval via URL SRU - Agregadores de contenido RSS R 


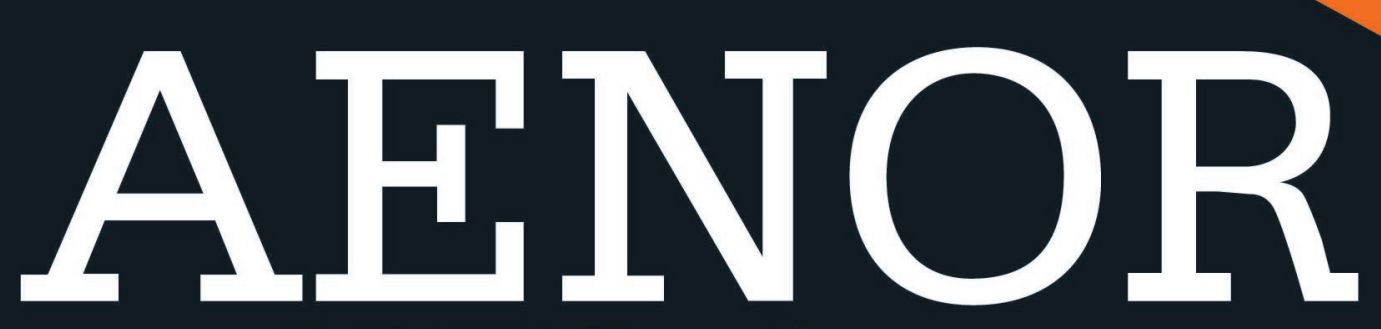

www.aenor.es $\square 902102201 \square$ comercial@aenor.es

Esta publicación contiene las claves que le ayudarán a salvaguardar la informaciōn generada en su empresa desde una doble perspectiva: la gestión de los documentos y la aplicación de las tecnologias de la información.

Recopila un conjunto de normas UNE con los requisitos necesarios para:

- Controlar los documentos de su empresa.

- Analizar los procesos para la creaciōn, incorporaciōn y control de documentos.

- Aplicar los metadatos a la gestión de documentos.

- Utilizar el conjunto de metadatos Dublin Core para la descripción de recursos electrónicos.

- Conservar a largo plazo los documentos digitales.

- Demostrar la autenticidad de las copias electrónicas.

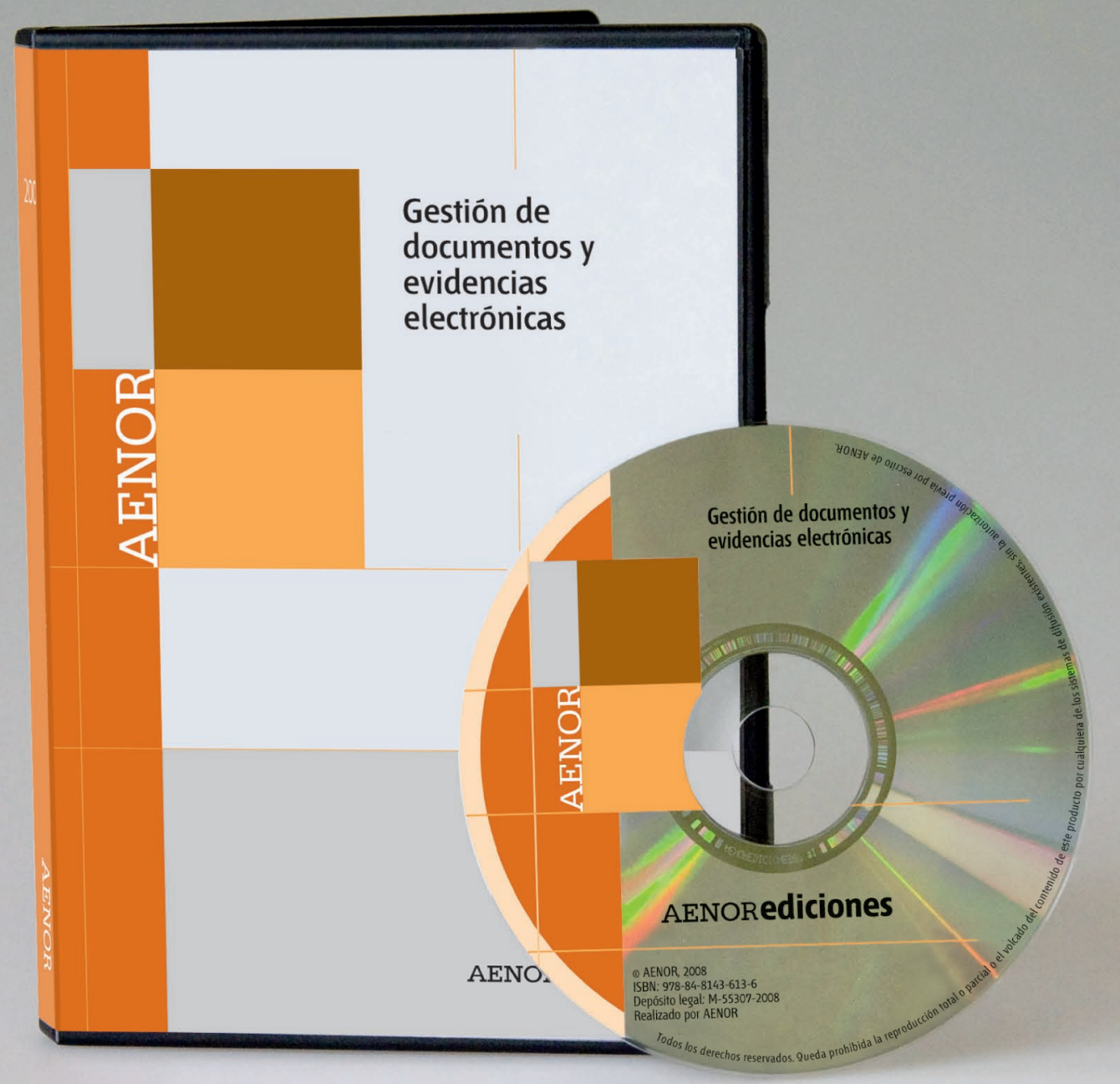

\section{Gestiōn de documentos}

Cómo controlar y proteger la información de su empresa

Buscar, encontrar y comprar... SUS LIBROS EN UN CIICK $5 \%$ de descuento

Manual de normas UNE 